\title{
COMPARATIVE ANALYSIS ON THE EFFICIENCY OF THE FIRM AND THEIRS DETERMINANTS OF EUROPEAN TRANSITION ECONOMICS
}

\author{
Justo de Jorge Moreno ${ }^{1}$, Leopoldo Laborda Castillo ${ }^{2}$ \\ ${ }^{1}$ Business Sciences Department, University of Alcala, \\ Plaza de la Victoria s/n 28802 Alcalá de Henares, Madrid,Spain \\ ${ }^{2}$ Institute of Latin American Studies (IELAT), University of Alcalá, c/ Trinidad $n^{\circ}$, \\ 28801 Alcalá de Henares, Madrid, Spain. \\ E-mails: 1justo.dejorge@uah.es (corresponding author); ${ }^{2}$ llabordacastillo@gmail.com
}

Received 11 January 2012; accepted 27 June 2012

\begin{abstract}
In this study we evaluate the efficiency of the firms with DEA technique and bootstrapping procedure in eleven transition economics among sixth industrial and service sectors in a cross-section 2005. At the second stage, we study the relationship between corrected efficiency scores and possible explanatory variables. On one hand, our result shows statistically significant differences in efficiency levels across countries and sectors. Likewise, significant levels of inefficiency are identified especially in service sectors (Hotels and Restaurants, Retail and Wholesale and Transport). On the others hand, the results of the analysis in second stage confirmed the existence of a significant relationship between the country that firms operate (country-effect) and firm's age (learning by doing). The latter relationship between age and efficiency has different behaviors according to the sector concerned, in the form of U shape in the Hotels and Restaurants, inverted U shape in Metal and Machinery and Wood and Furniture and linear in the Retail and Wholesale sector. Contrary perhaps to expectations, the results also allow us to conclude that there is no important statistically significant relationship between the efficiency and variables related to the strategies implemented by firms and the control of the property.
\end{abstract}

Keywords: DEA Bootstrap, transition economics, country effects, learning by doing, efficiency.

Reference to this paper should be made as follows: de Jorge Moreno, J.; Laborda Castillo, L. 2013. Comparative analysis on the efficiency of the firm and theirs determinants of European transition economics, Journal of Business Economics and Management 14(Supplement 1): S128-S144.

JEL Classification: F21, C34, O33.

\section{Introduction}

In this paper we evaluate efficiency of the firms in transition economics. We take eleven countries as a subject of investigation. This choice is not only motivated by our comparative advantage in knowing and availability of database this countries better than any other, but also because it is one of the interesting and difficult changing countries. In 
this sense, the changes in the social and economic policy environment will further enrich study. For example, authors like Bennett et al. 2007 study the difficulties and impact of the privatization process undertaken in the period 1990-2003. These authors mention that in practice, each country used a variety of privatization methods, with the choice of method depending on factors such as the political slant of the government, international debt, the levels of economic and institutional development, and enterprise specific factors.

Authors like Jones et al. 1998 mention that determinants of efficiency have been identified as a key issue concerning efficiency for firms in transition economies. Nevertheless the matter is also quite controversial. In this sense, the influence of firm's strategic like export-oriented, whether firms participate in joint ventures, the impact of different forms of ownership, and whether the effect of these variables might be expected to vary in the change from plan to market (Blanchard 1985; World Bank 1996).

Nevertheless, we are not aware of the existence of numerous studies conducted comparative studies of efficiency and theirs explanatory factors at firms-level in transition economics. These include Kravtsova 2008 who investigates foreign presence in the performance of domestic manufacturing firms for five transition countries (Bulgaria, Estonia, Hungary, Poland and Romania).

Recently, Tvaronaviciene et al. (2009) analyze if institutional performance matters in Lithuania, Latvia and Estonia after the European Union accession. Authors take into account that different approaches to countries' development assessment might affect their comparison results. These authors explore how much Lithuanian, Latvian and Estonian ranking according to estimated development level differs due to variations of approaches applied, and how sensitive calculations are to institutional performance and current economic downturn.

Taking into account this empirical background, in this study, we use a two-stage approach. At the first stage we estimated sensitivity efficiency scores using bootstrapping Data Envelopment Analysis (DEA). We analyze distributions of both original and corrected efficiency scores (via kernel density estimation). At the second, relationship between corrected efficiency scores and possible explanatory variables. We found statistically significant differences in efficiency levels across countries and sectors. Likewise, significant levels of inefficiency are identified especially in service sectors (Hotels and Restaurants, Retail and Wholesale and Transport). Regarding the factors that explain the efficiency country-effect where the firm operates and the firm's age have been significant. While the latter in firms belonging to four of the sixth sectors and with different behaviors in the form of curvilinear and linear shape.

The rest of the paper is organized as follows: section 1 shows characteristic of the countries, variable and data; section 2 presents the methodology; section 3 provides the main results and the last section offers the conclusions.

\section{Descriptive statistics, variables and data}

As has been mentioned, this work makes a comparative analysis of the efficiency of firms from eleven countries in transition economics. We have used firms located in: Bulgaria, Czech, Estonia, Hungary, Latvia, Lithuania, Moldova, Poland, Romania, Slo- 
vakia, and Slovenia. Tables 1 and 2 show the main features of the analyzed countries they belong to the firms and the numbers of firms analyzed by both countries and sectors respectively.

Table 1. Socio-economic and development indicators by country (2005)

\begin{tabular}{lcccccc}
\hline $\begin{array}{l}\text { Country/ } \\
\text { industry }\end{array}$ & $\begin{array}{c}\text { Total } \\
\text { population }\end{array}$ & $\begin{array}{c}\text { GDP per } \\
\text { capita, PPP }\end{array}$ & $\begin{array}{c}\text { Industry, } \\
\text { value added }\end{array}$ & $\begin{array}{c}\text { Domestic } \\
\text { credit private }_{\text {sector }}{ }^{7}\end{array}$ & $\begin{array}{c}\text { Inflation, } \\
\text { consumer } \\
\text { prices }^{8}\end{array}$ & $\begin{array}{c}\text { Procedures } \\
\text { to enforce } \\
\text { a contract }^{1}\end{array}$ \\
\hline Bulgaria & 7781000 & 8737.16 & 4022807808 & 36.31 & 6.34 & 34 \\
\hline Czech & 10206923 & 19094.62 & 22018136064 & 32.61 & 2.83 & 22 \\
\hline Estonia & 1348999 & 15107.31 & 1911966336 & 40.01 & 3.04 & 25 \\
\hline Hungary & 10107095 & 16306.48 & 15011529728 & 45.82 & 6.78 & 21 \\
\hline Latvia & 2312791 & 11885.7 & 2287386624 & 50.77 & 6.19 & 24 \\
\hline Lithuania & 3435585 & 12967.48 & 4650113536 & 28.80 & 1.19 & 24 \\
\hline Moldova & 3925170 & 2012.422 & 290329920 & 21.23 & 12.52 & 37 \\
\hline Poland & 38182200 & 13091.86 & 53077282816 & 28.14 & 3.57 & 41 \\
\hline Romania & 21684884 & 8977.65 & 15057262592 & 15.67 & 11.87 & 43 \\
\hline Slovakia & 5382449 & 14989.53 & 8776060928 & 30.54 & 7.54 & 27 \\
\hline Slovenia & 1997000 & 22132.83 & 7092050944 & 48.77 & 3.58 & 25 \\
\hline
\end{tabular}

Notes: ${ }^{1}$ Number; ${ }^{2}$ Constant 2005 international $\$ ;{ }^{3}$ Constant 2000 US\$; $\%$ of GDP; ${ }^{5}$ Annual $\%$. Source: DDP Quick Query database of WDI \& GDF, World Bank.

Table 2. Number of firms analyzed by both industry and country (year 2005)

\begin{tabular}{|c|c|c|c|c|c|c|}
\hline $\begin{array}{l}\text { Country/ } \\
\text { industry }\end{array}$ & $\begin{array}{l}\text { Hotels and } \\
\text { restaurants }\end{array}$ & $\begin{array}{c}\text { Retail and } \\
\text { wholesale trade }\end{array}$ & Transport & Construction & $\begin{array}{l}\text { Metals and } \\
\text { machinery }\end{array}$ & $\begin{array}{l}\text { Wood and } \\
\text { furniture }\end{array}$ \\
\hline Bulgaria & 14 & 71 & 21 & 15 & 9 & 3 \\
\hline Czech & 23 & 72 & 28 & 42 & 29 & 12 \\
\hline Estonia & 16 & 42 & 10 & 18 & 8 & 4 \\
\hline Hungary & 15 & 72 & 16 & 32 & 153 & 4 \\
\hline Latvia & 8 & 53 & 10 & 10 & 5 & 8 \\
\hline Lithuania & 15 & 38 & 23 & 19 & 8 & 10 \\
\hline Moldova & 7 & 46 & 4 & 3 & 20 & 3 \\
\hline Poland & 14 & 131 & 46 & 61 & 178 & 6 \\
\hline Romania & 14 & 52 & 8 & 23 & 86 & 6 \\
\hline Slovakia & 7 & 32 & 4 & 11 & 12 & 3 \\
\hline Slovenia & 15 & 27 & 14 & 21 & 23 & 5 \\
\hline Total & 148 & 636 & 184 & 255 & 531 & 64 \\
\hline
\end{tabular}

Source: DDP Quick Query database of WDI \& GDF, World Bank. 
As complement figure 1 represent both countries by GDP per capita according to intensity of color (percentile \#4, red color as high percentage of total value to percentile \#1 light yellow as low percentage and representative percentage of firms by sector and country)

As can be shown in Figure 1, percentile \#4 is integrated by Czech and Slovenia countries. Percentile \#3, Hungary, Slovakia and Estonia. Percentile \#2, Latvia, Lithuania and Poland. Finally in the percentile \#1, Romania, Moldova and Bulgaria. In relation to the representation of firms by both sectors and countries in the graphs on the right side of Figure 1, we can observe some interesting features. For example, in some countries the percentage of firms belonging to one sector dominates the rest; this is the case for Retail and Wholesale sector in Latvia and Bulgaria or Metals \& Machinery, in Poland, Romania and Hungary. A more balanced presence of firms in all sectors like in Slovenia, Czech and Lithuania.

The statistical source used for this analysis is the World Bank's Enterprise Surveys (ES) for 2005 (see World Bank 2009 for methodology details). The ES collect data from key manufacturing and service sectors in every region of the world. The Surveys use standardized survey instruments and a uniform sampling methodology to minimize measurement error and to yield data that are comparable across the world's economies.

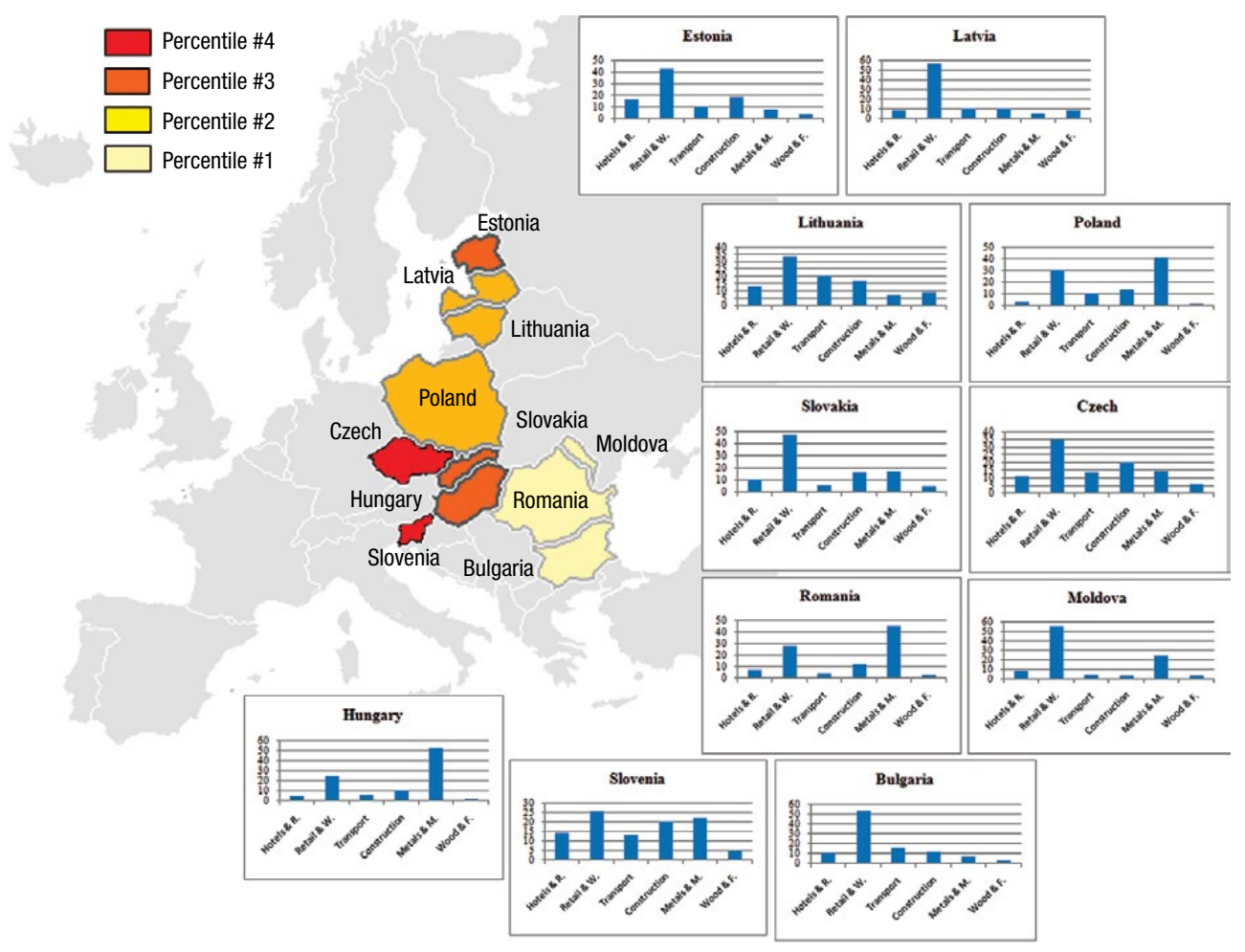

Fig. 1. GDP per capita according to percentile and representative percentage of firms by sector and country 
To generate internationally comparable data, the questions in the Core questionnaire are asked in all countries and for all industries where the survey is implemented. In addition to this Core instrument, the Manufacturing Module and Services Module questions are asked to establishments in the manufacturing and services sectors, respectively.

The sampling methodology of the World Bank's Enterprise Survey generates sample sizes appropriate to achieving two main objectives:

1. A sample representative of the whole economy that substantiates assertions about the whole economy, not only about the manufacturing sector. The overall sample should include, in addition to selected manufacturing industries, services industries and other relevant sectors of the economy.

2. A large enough sample size for selected industries to conduct statistically robust analyses with levels of precision at a minimum $7.5 \%$ for $90 \%$ confidence intervals about $^{1}$ : (a) estimates of population proportions (percentages), at the industry level, and (b) estimates of the mean of log of sales at the industry level.

To analyze the efficiency levels the choice of output and input types follows Donthu and Yoo's (1998) and Coelli et al. (2002) recommendations. The inputs are measured by three variables. The measure for labour is personnel cost (we can not use the number of employees variable as labour because there were a lot of missing values), being material and energy costs respectively the others inputs. Finally, output is measured by sales. All those variables are measured in US dollars according the PPP that OECD publishes. Let's note that using the number of employees (instead of the payroll) as a measure of size as other papers do, the sample sizes would have been reduced more than $40 \%$ due to missing values in the survey.

Concerning the explanatory reasons of the efficiency levels for second stage, although the requested information provides a vast array of possibilities, the actual information available imposes tight restrictions. After a careful analysis, we have chosen seven variables largely used in the literature: one of them make reference to the ownership structure (percentage of shares that the local owners hold), age of firm and five linked to the competitive characteristics (international quality certification, new product introduction, make joint venture, make licensing agreement and make outsourcing) with a binary character. Table A1 in appendix summarizes descriptive statistics of the selected variables.

\section{Methodology}

The research methodology consists of the following stages. First, a nonparametric methodology is used to measure the technical efficiency with DEA (see Charnes et al. 1978) to compare firms by sectors. Second, OLS regression will be used to determine the explanatory factors of corrected efficiency. The kernel distribution will provide a more specific analysis to know the shape of the industry efficiency distribution.

\footnotetext{
${ }^{1}$ A $7.5 \%$ precision of an estimate in a $90 \%$ confidence interval means that we can guarantee that the population parameter is within the $7.5 \%$ range of the observed sample parameter, except in $10 \%$ of the cases.
} 
To compute a production frontier and the technical efficiency indexes that it implies, can be done by econometric techniques or by mathematical programming. Each of these two approaches as its own advantages and disadvantages Authors as Lovell 1993 argue that "neither approach strictly dominates the other" meanwhile others such as Coelli, Rao and Battese 2002 suggest that "selection of the appropriate method should be made on a pragmatic basis". The last option has been chosen to carry on this analysis. Specifically, we use non-parametric DEA (Data Envelopment Analysis).

Some of the arguments in favour of this methodology lie in that it allows getting maximum information on the available data. In comparison with parametric approaches, DEA presents some virtues: It allows including multiple inputs and outputs with different unit measures, it explores the inefficiency origins quantifying over-use of inputs, and it does not require any initial hypothesis on the functional form of the production frontier ${ }^{2}$.

The current work uses an input-oriented model, since market in transition economics is better suited has a better intuition about the potential savings in inputs compared to the waste of resources, and because the different formats are subject to demand conditions, which leads them to adjust their inputs freely.

According to Färe et al. (1994) we propose the following input-oriented DEA model to measure the technical efficiency:

$$
\begin{gathered}
\operatorname{Min} \lambda \\
\lambda, z \\
\text { s.t: } \\
\operatorname{ujm} \leq \sum_{\mathrm{j}=1}^{\mathrm{J}} \mathrm{z}_{\mathrm{j}} \mathrm{u}_{\mathrm{jm}}, \mathrm{m}=1,2, \ldots, \mathrm{M}, \\
\sum_{j=1}^{J} \mathrm{z}_{\mathrm{j}} \mathrm{u}_{\mathrm{jn}} \leq \lambda x_{\mathrm{jn}}, \mathrm{n}=1,2, \ldots, \mathrm{N}, \\
\mathrm{z}_{\mathrm{j}} \geq 0, \mathrm{j}=1,2, \ldots . . \mathrm{J},
\end{gathered}
$$

where: 1 = efficiency measure to be calculated for each DMU j, ujm = quantity of output $\mathrm{m}$ produced by DMU j, xjn = quantity of input $\mathrm{n}$ used by $\mathrm{DMU} \mathrm{j}$, and $\mathrm{zj}=$ intensity variable for $\mathrm{DMU} \mathrm{j}$.

Since the variable 1 is calculated for each DMU, the preceding formulation is estimated once for each DMU in the data set. Equations 1,2 and 3 define a set of constraints for each output and input. A value of $1=1$ means that a firm is considered efficient, while a value $1<1$ means a firm is inefficient. For each DMU, we solve the linear program problem exposed.

The DEA method of estimating efficiency has received some opposition (see Henderson and Zelenyuk 2004). Traditional DEA assumes that no measurement error exists

\footnotetext{
${ }^{2}$ Besides, in cases like this one, a cross-section regression has little information to establish which part of the error term can be attributed to the perturbation and to the inefficiency component (Lovell 1993). However, DEA does not require any assumption on the statistical distribution of the error term.
} 
and estimated production frontier is piecewise linear. Koop et al. (2000) mention that sensitivity of DEA outliers is no doubt one of the weaknesses of the DEA approach. As mentioned by (Daraio and Simar 2006), the DEA efficiency score is a performance indicator obtained by comparing each firm with the best performers of its objective group; i.e. the benchmarking is, in a certain sense, severe for each firm and sensitive to extremely performing firms to answer these comments, (Simar and Wilson 1998, 2000) and others have introduced bootstrapping into DEA framework. Their methods, based on statically well-defined models, allow for consistent estimation of the production frontier, corresponding efficiency scores as well as standard errors and confidence intervals. The idea of the bootstrap is to simulate repeatedly the data generating process using the resampling method and applying the DEA to each simulated sample so that the resulting DEA efficiency indices mimic the sampling distribution of the original DEA efficiency indices. In this paper, we employ the bootstrap procedure suggested by Simar and Wilson 1998.

\section{Research results ${ }^{3}$}

\subsection{Distribution of original and corrected efficiency}

Figure 2 shows the evolution of both original and corrected technical efficiency by sector. These figures represent the entire distribution using box plots and violin plots ${ }^{4}$ corresponding to all the firms, which enables the features of the distributions to be detected more thoroughly. The white dot indicates the median and the black bar the first and third quartile. Accordingly, each figure contains both the box plots and the density trace, which is plotted symmetrically to the left and right of the vertical box plot. In the case of both original and corrected efficiency by sectors firms, we can observe different behaviours in relation to the distribution of the efficiency (more or less concentrated or with one or more modes) of the companies. For example, Metal \& Machinery and Retail and Wholesale sectors have a unique mode compared to the other four sectors where its can see generally two modes for minimum and maximum values of efficiency. Also the range of distribution is lower in the case of Wood and Furniture and Construction sectors in relation to the other four.

\subsection{Efficiency differences by industries and countries}

Table 3 contains the DEA analysis results on the average corrected efficiency of each of the six considered activities. The line "global frontier" presents the average efficiency of Hotels and Restaurants, Retail and Wholesale, Transport, Construction, Metals and

\footnotetext{
${ }^{3}$ We used the software Packaged FEAR by Wilson (2007), which can be implemented in the statistical software R.

${ }^{4}$ Violin plots are a mixture of box plots and density functions estimated non-parametrically via kernel smoothing, to reveal structure found within the data. Box plots show four main features of a variable: center, spread, asymmetry and outliers. The density trace, which in the case of violin plots is duplicated for illustrating purposes, supplements this information by graphically showing the distributional characteristics of batches of data such as multi-modality.
} 

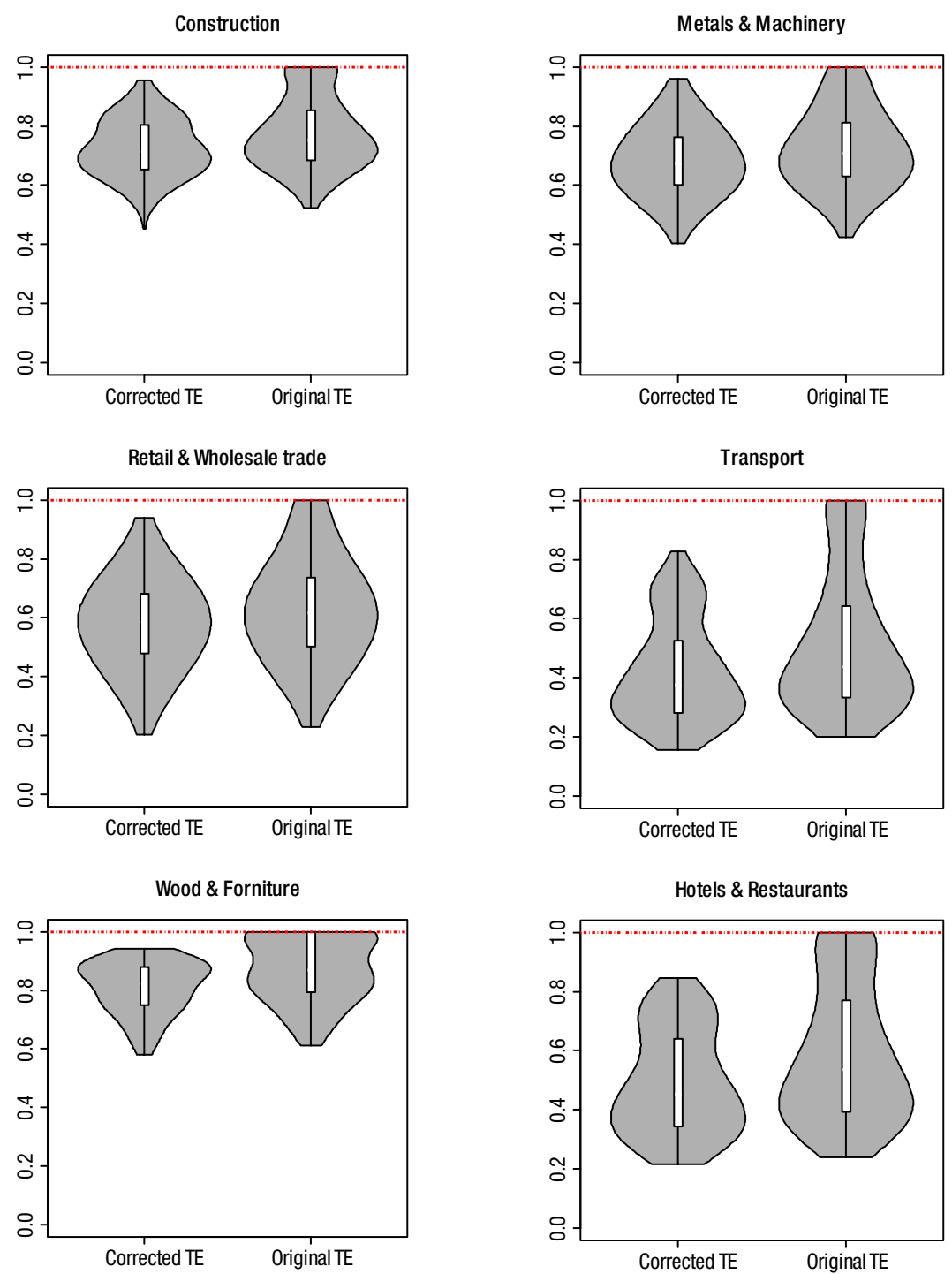

Fig. 2. Comparison original and corrected technical efficiency by sector

Machinery and Wood and Furniture with values of 52.37, 57.86, 43.65, 71.86, 70.83 and 80.14 per 100 respectively 5 . These results means that firms in this activities could get the same amount of output with a potential input saving of 47.63, 42.14, 56.35, $28.14,29.17$ and $19.86 \%$ respectively, which supposes levels of inefficiency, especially in service activities (Hotels and Restaurants, Retail and Wholesale, Transport).

\footnotetext{
${ }^{5}$ There are statistically significant differences among the six sectoral efficiency distributions test Kruskal Wallis $572.82(0.000)^{* * *}$.
} 


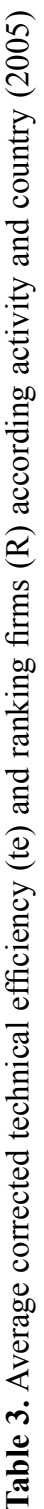

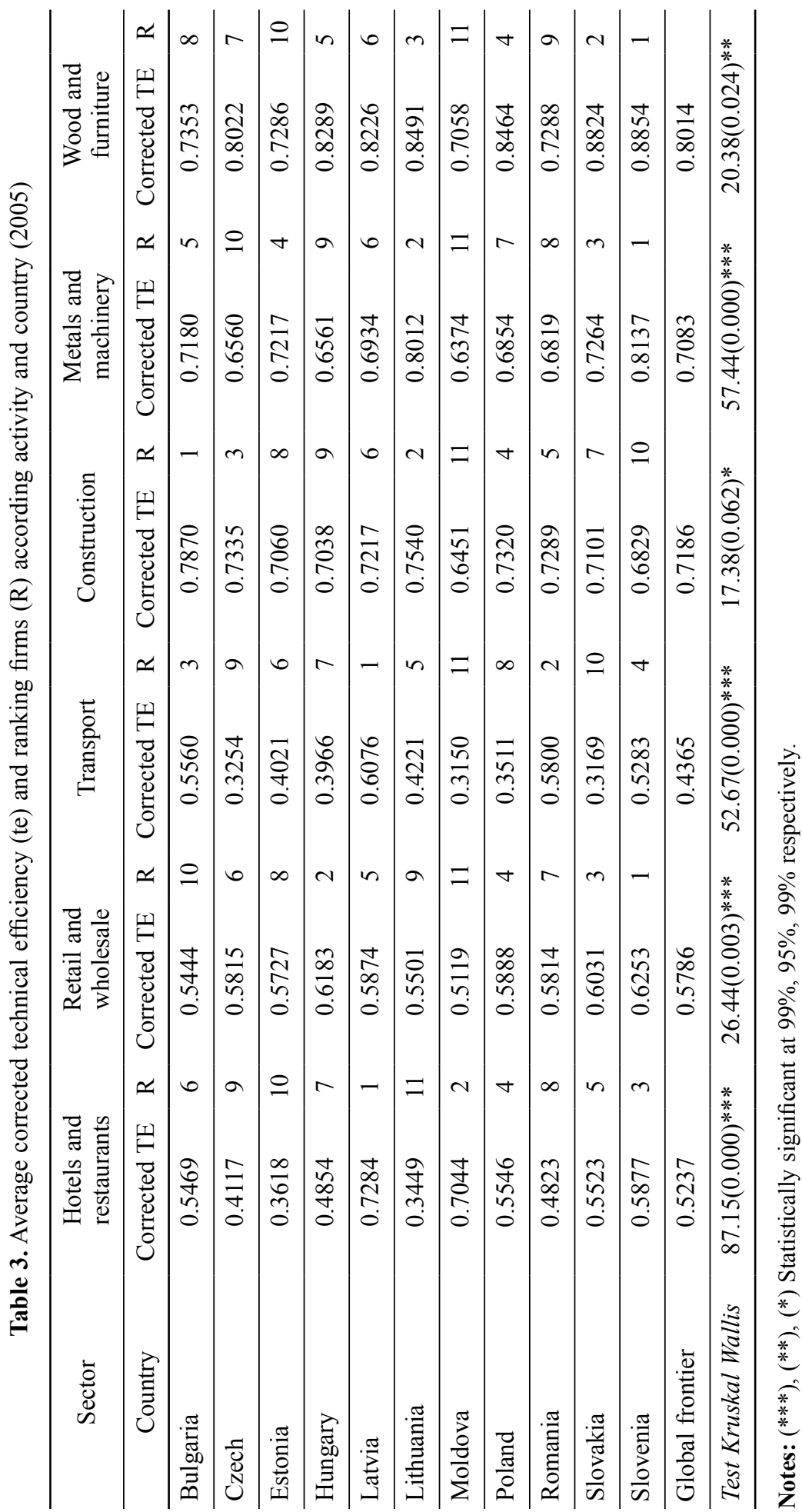



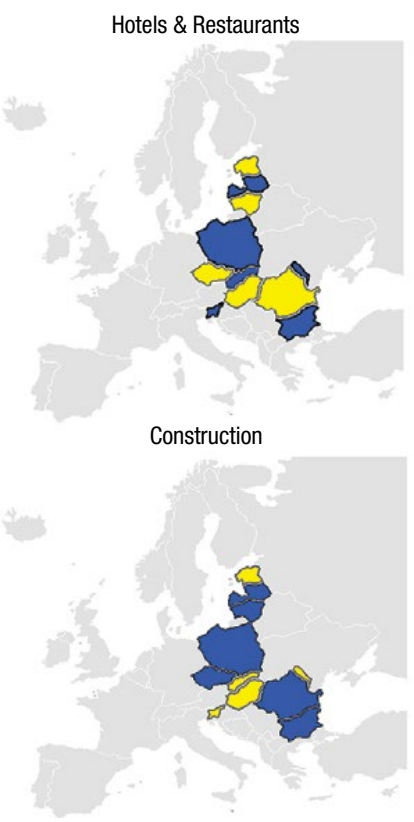

Above the global frontier
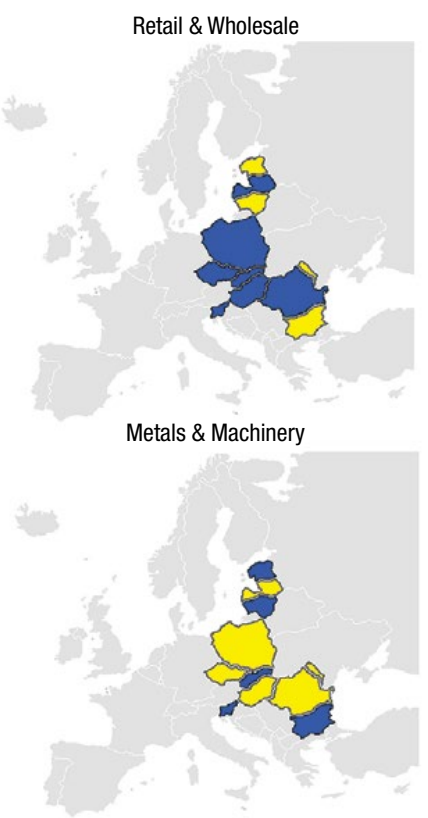

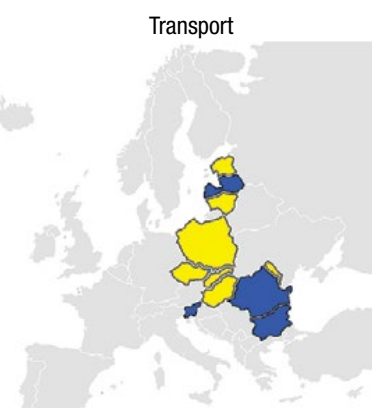

Wood \& Furniture

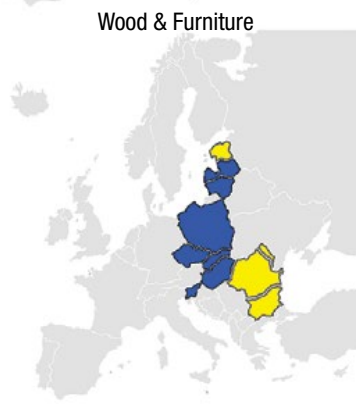

Fig. 3. Levels of efficiency firms by both sectors and country according global frontier

The analysis of the average corrected efficiency of firms in each country in comparison with the activity, for sixth sector shows that; Slovenia and Latvia firms are above global frontier en table 5 sectors. Poland, Bulgaria and Slovakia in Table 4, Romania, Lithuania and Czech in Table 3, Hungary in Table 2 and finally Estonia and Moldova in Table 1. Figure 3 shows the levels of efficiency for countries above the global frontier in blue color or below in yellow. In the case of Hotels and Restaurants, Retail and Restaurants, Construction and Wood and Furniture over 50\% of countries analyzed is above the global frontier. However, in the sectors Transport and Metals and Machinery less than $50 \%$ remain in that position.

\subsection{Determinants of corrected efficiency}

Having analyzed the dynamic evolution of corrected efficiency, the next step is to study what their determining factors are. The dependent variable $\theta_{i, t}$ is the corrected efficiency. In this sense we avoid one of the problems in the estimation of the second stage, since our dependent variable it is not truncated. As can be seen in Table 4, there were significant statistical differences in relation to the country where firms do business (country-effect). Also the firm's age in four sectors (Hotels and Restaurants, Metals and machinery, Wood and Furniture sectors appears as a determinant factor of efficiency, but with different behavior as will be see later. However, the set of dummy variables that characterize the strategic behavior of firms in terms of organizational practices have little or no relevance. For firms belonging to Construction sector new product introduction is positively relationship with efficiency level. In the case of firms belong- 


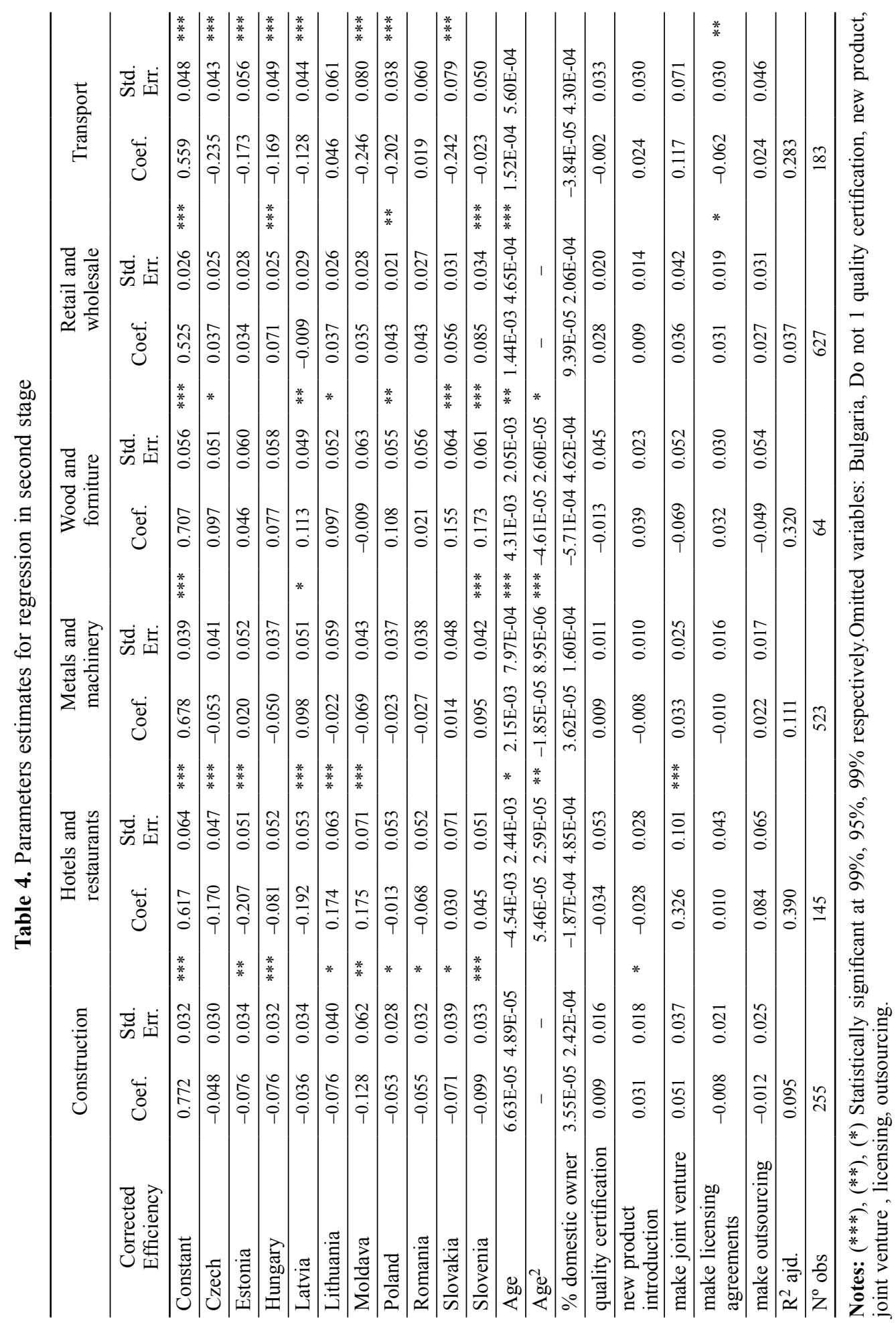


ing to sector Hotels and Restaurants perform joint venture is related to higher levels of efficiency. Make license agreements is also positively relationship with efficiency in Retail and Wholesale sector. These two strategies may lead to transfer of technology and managerial expertise.

Despite this low significance of the variables related to the strategies implemented by firms could be related to several factors, the low percentage of companies which occasionally puts out these actions and the presence of country effects and age as dominant. The percentage of shares in local power is not significant in any sector. Therefore greater control of the property is not associated with higher levels of efficiency.

Deepening on the latter effect, two opposite results may be considered. This is, the absence of statistical significant that age has on efficiency in the sectors of Construction and Transportation ${ }^{6}$. A possible explanation for this might relate to the older firms may have more experience in the market (learning by doing), but may be less flexible and dynamic than younger, which could affect the firm's ability to adjust to the market. However, the introduction of new products has a positive effect on efficiency in the Construction sector, while firms that have licensing agreements are more efficient in the Transport sector. In relation to the sectors where the firm's age is associated with efficiency levels, Figure 4 shows the different trajectories.

In the case of sector Hotels \& Restaurants relationship is U-shaped where the average age is in the negative slope (red vertical line) this relationship between efficiency and age may indicate the need for a significant level of expertise in market knowledge to become more efficient. In other words, established firms maintain a significant market power. In the other three sectors the relationship between efficiency and age is positive, inverted U-shaped for sectors Metals \& Machinery and Wood and Furniture where the average is in the positive slope and linear trajectory for the sector Retail and Wholesale. In this sense, generally speaking, greater seniority affords the firm greater know-how, which can lead to a greater capacity for developing its activities in a more efficient way. Firm experience, might be related to technical efficiency since firm production might involve "learning by doing".

\section{Conclusions}

In this study we evaluate de efficiency firms with DEA technique and bootstrapping procedure in eleven transition economics among sixth industrial and service sectors in a cross-section 2005. At the second stage, we study the relationship between corrected efficiency scores and possible explanatory variables. Benchmark analysis in first stage made it possible to detect resource management carried out by managers in a sector with turbulent environment. We found statistically significant differences in efficiency

\footnotetext{
${ }^{6}$ In order to have stronger results in our model we estimate a new non parametric regression model, but we could not improve our findings by comparing with the parametric model. For example the variables age and domestic owner were not significant in the new model. These findings were similar in the rest of sectors.
} 

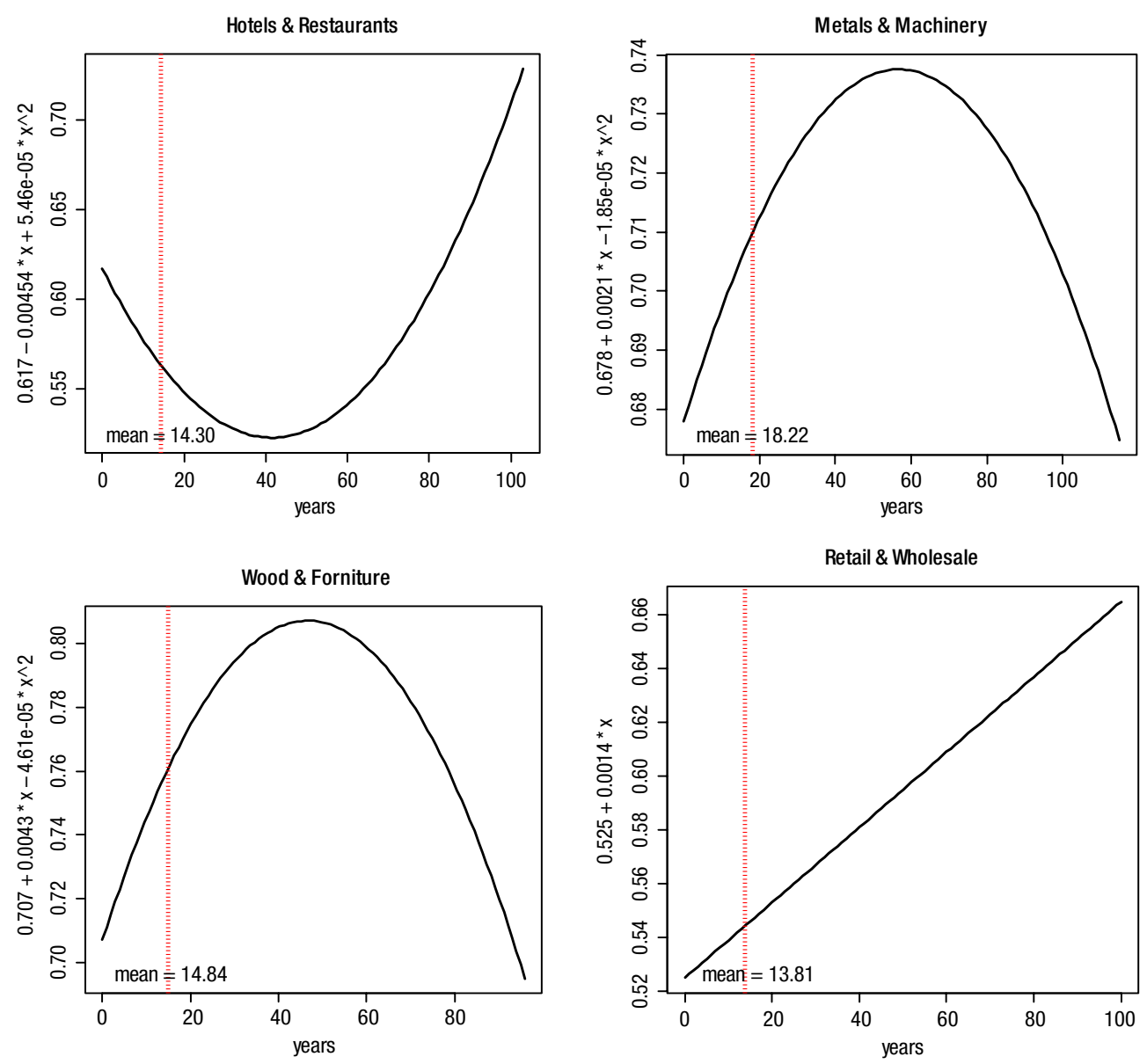

Fig. 4. Different patterns of the relationship between age and corrected efficiency

levels across countries and sectors in benchmark analysis. Likewise, significant levels of inefficiency are identified especially in service sectors (Hotels and Restaurants, Retail and Wholesale and Transport).

In relation to the determinants of efficiency, and according to Caves and Barton (1990) and Caves (1992), several studies have developed a strategy to identify the determinants of efficiency 1) Factors outside the company, such as the degree of competitiveness in the market where the company operates. 2) Characteristics of the company as the company size, type of organization, greater or lesser intensity of the investments made and the benefits of localization. 3) Deviations business dynamics of the situation of long-run equilibrium. These deviations may be the consequences of changes in demand facing the firm, or the consequence of certain production strategies such as the degree of technological innovation. 4) Public or private property. The degree of intervention in the management of the business manager can affect the degree of efficiency in the use of productive factor. The results of the analysis in second stage confirmed the existence 
of a significant relationship between the country that firms operate (country-effect) and firm's age. The latter relationship between age and efficiency has different behaviors according to the sector concerned, in the form of $U$ shape in the Hotels \& Restaurants, inverted U shape in Metal \& Machinery and Wood \& Furniture and linear in the Retail $\&$ Wholesale sector.

Contrary perhaps to expectations, the results also allow us to conclude that there is no important statistically significant relationship between the efficiency and variables related to the strategies implemented by firms and the control of the property, perhaps due to the dominance influence of the country-effect and the experience (learning by doing)

The results of this paper should be considered with some caution as a consequence of the cross-section analysis. Given the consequences that the efficiency has for a firm a main recommendation will be the need to be very conscious of the huge possibilities that do exist for a large part of the firms in transition economies, and the significant amount of resources that could be saved ${ }^{7}$. A second recommendation could be to continue to investigate to the low significance of strategy firms. In this line, panel data is perhaps the more appropriate way to obtain stylized facts but perhaps the difficulty of preparing such information is an important limitation.

\section{References}

Bennett, J.; Estrin, S.; Giovanni, U. 2007. Methods of privatization and economic growth, Economics of Transition 15(4): 661-683. http://dx.doi.org/10.1111/j.1468-0351.2007.00300.x

Blanchard, B. 1985. Exports, policy choices, and economic growth in developing countries after the 1973 Oil shock, Journal Development Economics 18(1): 23-25.

http://dx.doi.org/10.1016/0304-3878(85)90004-5

Caves, R.; Barton, D. 1990. Efficiency in US manufacturing industries. Cambridge: MIT Press, Mass.

Caves, R. 1992. Determinants of technical efficiency in Australia, in R. Caves (Ed.). Industrial efficiency in six nations. Cambridge: MIT Press, 241-272.

\footnotetext{
${ }^{7}$ In this context, based on inputs from governments, independent experts and the private sector in every economy, and using over 100 indicators, the OECD Investment Reform Index (IRI) 2010 assesses investment-related policy settings and reform against international best practice. The key findings and recommendations are: (1) Economies in East Europe (EE) have progressively reduced restrictions to national treatment since completion of the previous Investment Reform Index (IRI) 2006; (2) Governments in EE must address skills development on an urgent basis given the long response time of human capital policies and the global increase in demand for skills; (3) Since the IRI 2006, the EE economies have strengthened their ties with the multilateral trading system and furthered intra-regional trade; (4) Limited access to finance is a major concern of entrepreneurs in SEE. This problem has been accentuated by the global financial crisis; (5) Most EE economies have progressed in establishing institutional and legal frameworks for regulatory reform and in implementing reform; (6) In recent years EE economies have made important progress in strengthening their capacity to carry out tax policy development and implementation, regularly forecasting aggregate tax revenues and monitoring public revenues and expenditures; (7) EE economies have considerably improved their legal frameworks on infrastructure. Recent reforms are largely in compliance with EU standards and aim at fulfilling the EU acquis requirements.
} 
Coelli, T, D. S.; Rao, P.; Battese, G. 2002. An introduction to efficiency and productivity analysis. London: Kluwer Academic Publishers.

Charnes, A.; Cooper, W. W.; Rhodes, E. 1978. Measuring the efficiency of decision making units, European Journal Operation Research 2: 429-444.

http://dx.doi.org/10.1016/0377-2217(78)90138-8

Daraio, C.; Simar, L. 2006. A robust nonparametric approach to evaluate and explain the performance of mutual funds, European Journal Operation Research 175: 516-542.

http://dx.doi.org/10.1016/j.ejor.2005.06.010

Donthu, N.; Yoo, B. 1998. Retail productivity assessment using data envelopment analysis, Journal of Retailing 74(1): 89-105. http://dx.doi.org/10.1016/S0022-4359(99)80089-X

Färe, R.; Grosskopf, S.; Lovell, C. 1994. Production frontiers. New York, NY: Cambridge University Press.

Jones, D.; Klinedinst, M.; Rock, C. 1998. Productive efficiency during transition: evidence from Bulgarian panel data, Journal of comparative economics 26: 446-464.

http://dx.doi.org/10.1006/jcec.1998.1529

Henderson, D.; Zelenyuk, V. 2004. Testing for catching-up: statistical analysis of DEA efficiency estimates, Discussion Paper 0431. Institute of Statistics. Belgium: University Catholique de Louvain.

Koop, G.; Osiewalski, J.; Steel, M. F. J. 2000. Modelling the sources of output growth in a panel of countries, Journal of Business and Economic Statistics 18(3): 284-99.

Kravtsova, V. 2008. Foreign presence and efficiency in transition economies, Journal Productivity Analysis 29(2): 91-102. http://dx.doi.org/10.1007/s11123-007-0073-3

Lovell, C. A. K. 1993. Production frontier and productive efficiency, in H. O. Fried, C. A. K. Lovell, S. S. Schmidt (Eds.). The measurement of productive efficiency-techniques and applications. Oxford: Oxford University Press, 3-67.

OECD. 2010. Investment Reform Index IRI 2010: Monitoring Policies and Institutions for Direct Investment in South East Europe [online], [cited 11 January 2012]. Available from Internet: www. investmentcompact.org

Simar, L.; Wilson, P. W. 1998. Sensitivity analysis of efficiency scores: how to bootstrap in nonparametric frontier models, Management Science 44: 49-61.

http://dx.doi.org/10.1287/mnsc.44.1.49

Simar, L.; Wilson, P. W. 2000. Statistical inference in nonparametric frontier models: the state of the art, Journal of Productivity Analysis 13: 49-78. http://dx.doi.org/10.1023/A:1007864806704 Tvaronaviciene, M.; Grybaite, V.; Tvaronaviciene, A. 2009. If institutional performance matters: development: comparisons of Lithuania, Latvia and Estonia, Journal of Business Economics and Management 10(3): 271-278. http://dx.doi.org/10.3846/1611-1699.2009.10.271-278

World Bank, World Development Report. 1996. From plan to market. Oxford, UK: Oxford University Press for the World Bank.

World Bank 2009. Enterprise Survey and Indicator surveys: Sampling Methodology [online], [cited 11 January 2012 ]. Available from Internet: http://www.enterprisesurveys.org

Wilson, P. 2007. FEAR: a software package for frontier efficiency analysis with $R$ [online], [cited 11 January 2012 ]. Available from Internet: http://www.clemson.edu/economics/faculty/wilson/ Software/FEAR/fear.html 


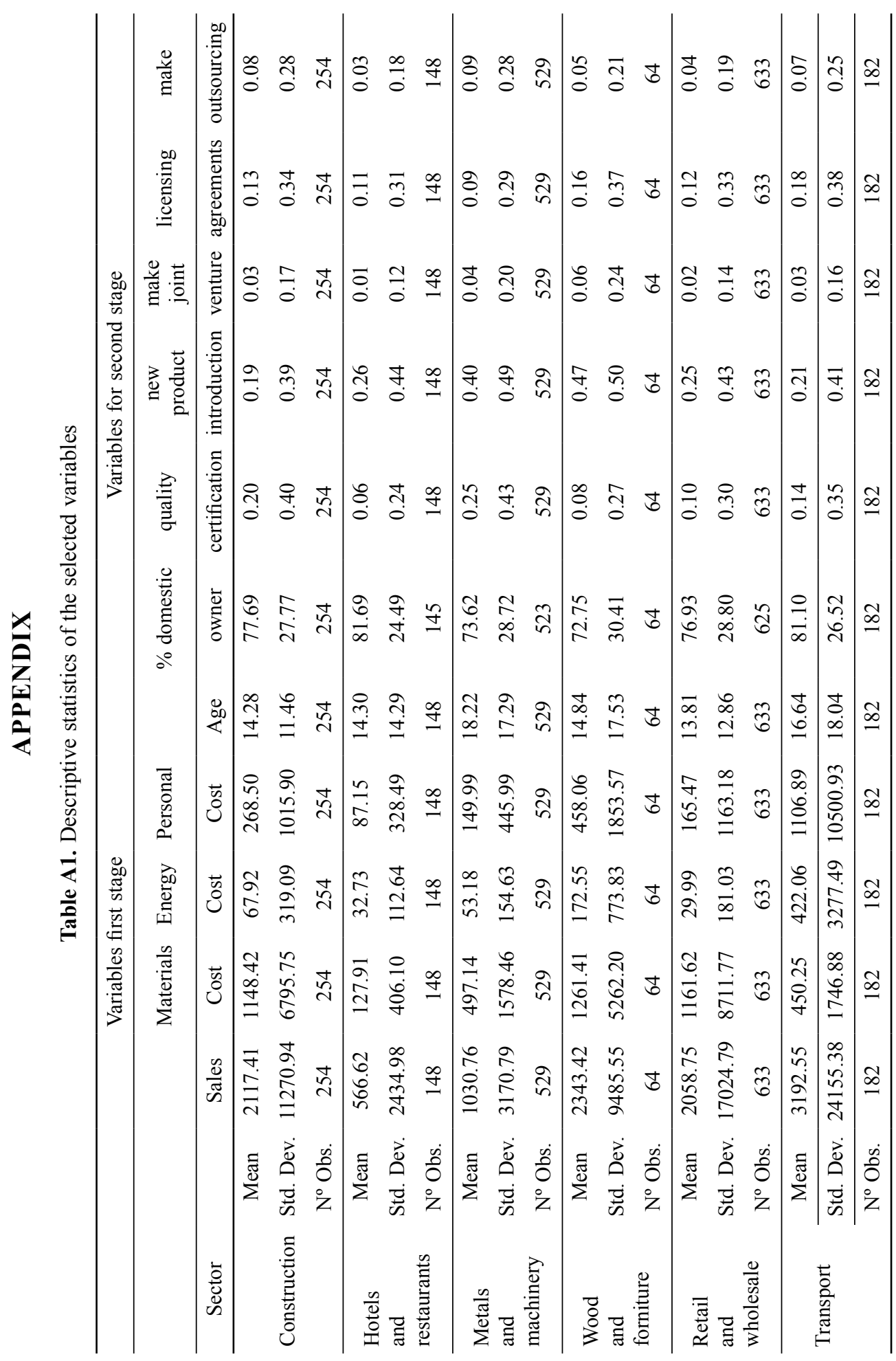


Justo DE JORGE MORENO is a Titular Professor in the Business Department of the University of Alcala(Madrid). Some of his articles have been published in Entrepreneurship Regional and Development, Annals of Regional, The Service Industry Journal, Journal of Business Economics and Management. Justo de Jorge Moreno can be contacted at: justo.dejorge@uah.es.

Leopoldo LABORDA CASTILLO. He works as STC at the World Bank and as Associated Professor at the University of Alcala (Spain). He received his $\mathrm{PhD}$ from University of Alcala. His research focuses on productivity and efficiency analysis in public and private sector. 